\title{
Facile synthesis and catalytic studies of CdS-manganese oxide nanocomposite
}

\author{
R. Kannan $\cdot$ K. Karunakaran $\cdot$ S. Vasanthkumar
}

Received: 3 August 2011/Accepted: 25 August 2011/Published online: 13 September 2011

(C) The Author(s) 2011. This article is published with open access at Springerlink.com

\begin{abstract}
Cadmium sulfide (CdS)-manganese oxide (MO) nanocomposite was synthesized by the ion exchange and ultrasonic irradiation methods. The synthesized nanocomposite was characterized by FTIR, powder X-ray diffractrogram (XRD), UV-Vis diffused reflectance spectra (UVDRS), photoluminescence (PL), transmission electron microscope (TEM) and energy dispersive X-ray analysis (EDX). The experimental results confirm the formation of CdS-MO nanocomposite. The luminescence of the nanocomposite exhibits a notable blue shift. The TEM results disclosed the size of the nanocomposite to be within $10-20 \mathrm{~nm}$. The catalytic activity of the nanocomposite was evaluated by the degradation of methylene blue (MB) under visible light.
\end{abstract}

Keywords Cadmium sulfide - Manganese oxide · Ion exchange $\cdot$ Ultrasonication $\cdot$ Nanocomposite

\section{Introduction}

Cadmium sulfide (CdS) semiconductor nanoparticles have attracted intense interest due to their unique photochemical and photophysical properties. They find immense applications in solar cell, hydrogen production, water splitting, etc. (Dameron et al. 1989; Pal et al. 1997; Dekany et al. 1999; Ramasubbu et al. 2000; Han et al. 2005). CdS is a

R. Kannan · K. Karunakaran

Department of Chemistry, Sona College of Technology,

Salem 636 005, India

R. Kannan $\cdot$ S. Vasanthkumar $(\bowtie)$

Centre for Research in Nanotechnology, School of Nanosciences and Technology, Karunya University, Coimbatore 641 114, India e-mail: kumar2359@yahoo.com semiconductor with a narrow band gap of $2.4 \mathrm{eV}$, and its valence electron can be easily excited to the conduction band under visible light irradiation. However, in aqueous solution, it is prone to aggregate into big metallic clusters, thereby losing its catalytic activity (Dameron et al. 1989; Pal et al. 1997). This can be overcome by stabilizing the nanoparticles using a surfactant (Dekany et al. 1999; Ramasubbu et al. 2000) which may not be suitable for direct applications. Thus, a solid matrix would be the better host to stabilize these nanoparticles. It is well documented that supported $\mathrm{CdS}$ has a performance superior to that of unsupported CdS (Ramasubbu et al. 2000; Han et al. 2005), because of the active ingredient (CdS) that is dispersed on the support. The supports provide heterojunctions for electrons and holes that restrict the charge recombination (Shangguan and Yoshida 2001). On the other hand, the recovery and recyclability of the catalyst is easy. The selection of the matrix for composite materials containing $\mathrm{CdS}$ depends on the material's application.

Manganese oxides (MO) are one of the largest families of porous materials with various structures as manganese oxide minerals are found all over the world. Two major structures are important, (1) octahedral layer constructed by edge sharing $\mathrm{MnO}_{6}$ to form sheets with cations $\left(\mathrm{Na}^{+}\right.$, $\mathrm{K}^{+}$) and in which water is present in between any two adjacent sheets, and (2) octahedral molecular sieve (OMS) materials constructed by the edge and corner shared octahedral $\mathrm{MnO}_{6}$ (Ma et al. 2006; Suib 2008) that find potential applications in the field of cation-exchange, ion and molecule separation, adsorbents, sensor, battery, catalysis (Ma et al. 2006; Suib 2008; Feng et al. 1999; Feng 2010), etc., Manganese oxide materials have been used for a wide range of catalytic applications in both synthetic chemistry and environmental problems, such as degradation of dyes, organic pollutants, waste water treatment, nitric oxide 
reduction, ozone decomposition and selective oxidation of CO (Shen et al. 1993; Segal et al. 1997; Zhang et al. 2006; Chen et al. 1997, 2001; Kannan et al. 2011; Xia et al. 1999).

There is considerable interest in preparing nanoparticles stabilized solid host, which consists of a highly dispersed metal phase on a high surface area of a solid support. Very few research groups have studied and explained the effect of CdS nanoparticles incorporated solid hosts, such as metal oxides, natural clays, synthetic clays, zeolite and MCM-41 (Han et al. 2005; Ma et al. 2006; Khaorapaponga et al. 2008). Recently, our research group has explained the photochemical degradation of organic dye using polyoxometalates- $\mathrm{MnO}_{2}$ nanocomposite (Kannan et al. 2011). In the same fashion an attempt was made to synthesis CdS impregnated manganese oxide by ion exchange and ultrasonication methods.

The manganese oxide has a featureless absorption over an entire wavelength range of $200-800 \mathrm{~nm}$, whereas the nano manganese oxide have an absorption peak centered around $380 \mathrm{~nm}$ (Sakai et al. 2005), which gets into the visible region by the incorporation of a photochemically active compound. Thus, a photogenerated electron in guest (CdS nano-pillars) quickly transfers through the interlayers into the surfaces of manganese oxide matrix makes the material more active and highly stable. In the present investigation, we present a simple method for the synthesis of CdS into the manganese oxide layer. The photocatalytic activity was disclosed during the degradation of organic (Methylene blue) dye.

\section{Experimental}

Synthesis of CdS-MO nanocomposite

The synthesis of CdS-MO was carried out in a two stage process. The MO xerogel was prepared according to the reported method (Xia et al. 1999). An aqueous solution of $1.4 \mathrm{~mol}$ (in $20 \mathrm{ml}$ ) of sucrose was quickly added to $0.38 \mathrm{~mol}(50 \mathrm{ml}$ in Double Distilled Water-DDW) of $\mathrm{KMnO}_{4}$ resulting in a rapid exothermic reaction leading to a brown colored gel formation. The gel was washed with DDW, and dried at $400^{\circ} \mathrm{C}$. The resultant blackish brown MO powder was dispersed in DDW and to this solution, an aqueous solution of cadmium nitrate $(0.25 \mathrm{~mm})$ was added with constant stirring. After $12 \mathrm{~h}$, the composite was formed and it was washed several times with water, filtered and dried at $80^{\circ} \mathrm{C}$. This dried sample was resuspended in $50 \mathrm{ml}$ water and hydrogen sulfide gas was purged into it, and the whole reaction was carried out in an ultrasonic bath. After $30 \mathrm{~min}$, the composite was washed and dried in an oven at $100^{\circ} \mathrm{C}$ for $12 \mathrm{~h}$.
The prepared nanocomposite was characterized by powder X-ray diffraction (XRD, Cu Kalpha $1.54178 \AA$, and Shimadzu XRD X-600). The UV-Vis DRS spectrum of the composite was recorded on a Shimadzu 2550 and the PL spectra were obtained using a Flurolog 3 luminescence spectrometer. The transmission electron microscopy images were taken using a Philips 200 instrument, and the energy dispersive X-ray analysis using INSTA, Oxford instruments for elemental analysis.

\section{Photocatalytic studies}

The catalytic capacity of the composite was tested for the decolorization of methylene blue (CI no 52015) dye. The catalytic studies were carried out in a closed chamber consisting of a jacketed quarts tube of $3 \mathrm{~cm}$ inner dia, $4 \mathrm{~cm}$ outer dia, and length of $15 \mathrm{~cm}$ and an outer Pyrex glass reactor of $6.5 \mathrm{~cm}$ inner dia. The visible light was provided by a mercury vapor lamp. The entire chamber was cooled with continuous water circulation.

About $100 \mathrm{ml}$ of the dye solution (MB $32 \mathrm{mg} / \mathrm{L}$ ), and $100 \mathrm{mg} / \mathrm{L}$ of catalysts were added and the mixture was allowed to react at room temperature with continuous stirring. At regular time intervals, $1 \mathrm{ml}$ of the mixture solution was pipetted out into a volumetric flask and diluted with distilled water to $20 \mathrm{ml}$ prior to the analysis. For optical absorption measurements, the diluted solution was immediately centrifuged in order to remove the catalyst particles. The centrifuged dye solution was then put into a quartz cell (path length $1.0 \mathrm{~cm}$ ) and the absorption spectrum was measured with a Shimadzu UV-1800 ultraviolet-visible (UV-Vis) spectrophotometer at $\left(\lambda_{\max }=\right.$ $664 \mathrm{~nm}$ ). The degradation products of the MB dye were analyzed using a (TOC-V CPH/CPN, Shimadzu, Japan) equipment.

\section{Results and discussion}

\section{Powder XRD Studies of CdS-MO}

Figure 1 shows the XRD pattern of the prepared $\mathrm{MO}, \mathrm{Cd}^{2+}$ and CdS impregnated MO nanocomposite. Pure MO exhibiting a strong peak at $(2 \theta=) 11.1$ with the inter layer spacing of $7 \AA$ confirms the formation of layered manganese oxide. The $\mathrm{Cd}^{2+}$ ion exchange MO shows similar XRD pattern with the increased inter lamellar space of $7.9 \AA$. This is higher than the pure MO. The CdS-MO nanocomposite exhibits a peak at $(2 \theta=) 11.9$ [7.2 $\AA$ ], which indicates that a stable composite was formed and the slight shift of peak position is due to the transformation of a layered structure into the closed structure of the manganese oxide. The final reduction of the lamellar size from 7.9 to 


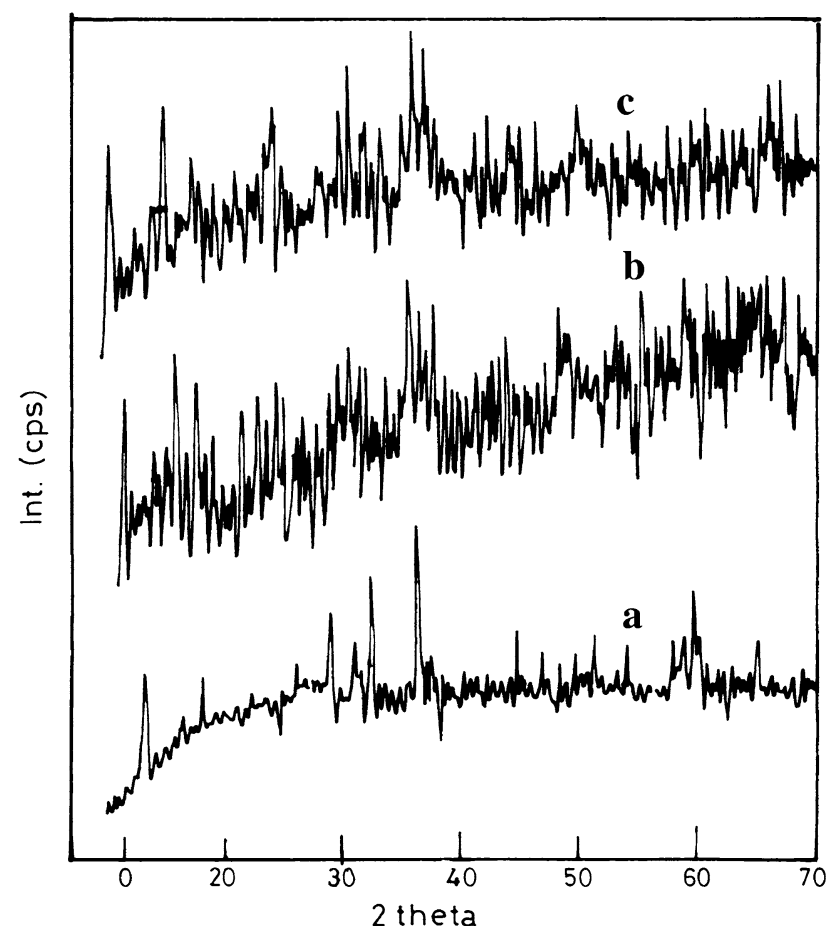

Fig. 1 Powder $X$ - ray diffraction patterns of the a manganese oxide, b $\mathrm{Cd}^{2+}$-manganese oxide and c CdS-manganese oxide nanocomposite

$7.2 \AA$ was due to the loosely bounded hydrated molecules expelled from the layer (Scheme 1). The interplanner distance of the pure $\mathrm{MO}$ and $\mathrm{CdS}-\mathrm{MO}$ nanocomposite is almost the same, indicating that the dimension of the CdS particles is restricted by the MO sheets to 7-7.2 $\AA$. The presence of CdS was confirmed by EDX spectra (Scheme 1).

The FTIR spectra recorded for the MO, CdS-MO samples showed significant IR signals at different frequency range. The broad and strong peak at $3,442 \mathrm{~cm}^{-1}$ and the one at $1,640 \mathrm{~cm}^{-1}$ correspond to the $\mathrm{O}-\mathrm{H}_{\text {str }}$, and $\mathrm{O}-\mathrm{H}_{\text {bending }}$ frequencies respectively for the adsorbed water present in the sample (Fig 2a, b). The MO, CdS-MO material showed similar adsorbtion bands at 408, 515 and $710 \mathrm{~cm}^{-1}$, which was in good agreement with the MO material of layered with tunnel structures (Kang et al. 2007). After the degradation of the organic dye, the degradation products were absorbed on the catalyst (Fig. 2c). The characteristic peak at $515 \mathrm{~cm}^{-1}$ confirmed the retaining of the layered structure of MO after the photocatalytic studies.

UV DRS and PL Studies of CdS-MO

The diffused reflectance spectra of the CdS-MO nanocomposite are shown in Fig. 3a. The absorption spectral peak is observed at $390 \mathrm{~nm}$. Compared to the pure CdS ( 470), the nanocomposite exhibits a distinct blue shift. The PL spectra of the CdS-MO nanocomposite (excited at $390 \mathrm{~nm}$ ) are shown in Fig. 3b. The results of the spectral photoluminescence measurements confirm the existence of CdS nanoparticles in the MO. The PL spectra shows two different peaks at 417 and $437 \mathrm{~nm}$ and the characteristic two-band structure of the emission spectra has also been observed by other researchers (Ma et al. 2006), who have explained the former observation as evolving out of the direct recombination of the exciton pairs. The later observation is ascribed to a recombination of the exciton pairs via trap surface states. This exhibits a blue shift of about $33 \mathrm{~nm}$ when compared with the emission spectra of CdS. This is due to the quantum confinement of CdS nanoparticles (Shangguan and Yoshida 2001; Ma et al. 2006), and also due to the emission that occurs from the nanoparticles carrying several photons of $e^{-}-h^{+}$pair at the same time. Hence, the prepared nanocomposite material would be a suitable candidate for photochemical application.

\section{TEM and EDX analysis of CdS-MO nanocomposite}

Figure 4 shows the TEM images of synthesized CdS-MO nanocomposite with hierarchic structure. It clearly showed that the particles were in the nanodimension with particle size of $<20 \mathrm{~nm}$ and at a lower magnification images clearly shows a sandwich like structure. The intercalated CdS $(\sim 10 \mathrm{~nm})$ nanoparticles were clearly shown as the dark phase of the composite. The presence of cadmium and sulfide in the nanocomposite was tested by energy dispersive X-ray analysis. Figure $4 \mathrm{~b}$ provides an overview of the sample. The quantitative analysis of the composite discloses that the content of $\mathrm{S}$ in the general area was always greater than $\mathrm{Cd}^{2+}(\mathrm{Cd}$ is 8.7 atomic $\%$ and $\mathrm{S}$ is 9.1 atomic $\%$ ), which is in good agreement with the literature report (Han et al. 2005).
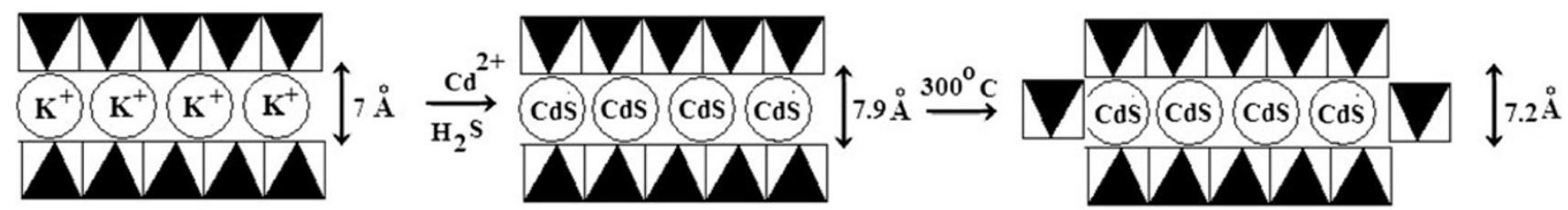

Scheme 1 Formation CdS-MO nanocomposite 


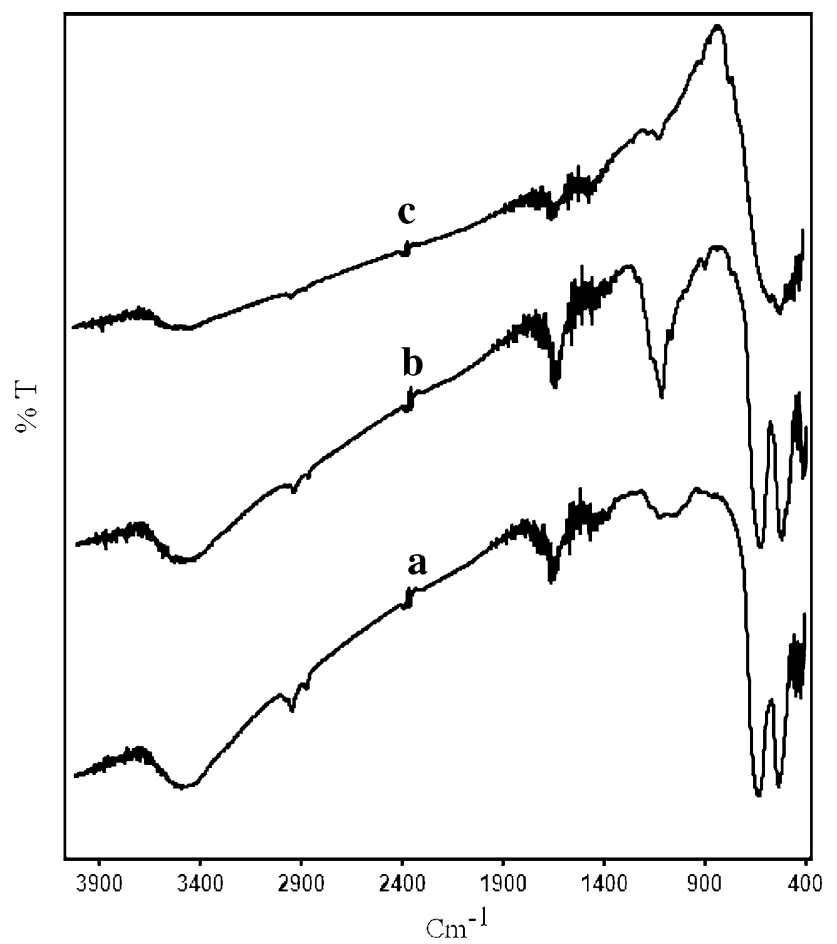

Fig. 2 FTIR spectrum of a manganese oxide, photocatalyst CdS-MO nanocomposite, $\mathbf{b}$ before and $\mathbf{c}$ after photocatalytic sruides

Photocatalytic studies on the decolorization of MB dye

The catalytic performance of the CdS-MO nanocomposite on the decolorization of the MB dye was studied. The absorbance of the MB with the initial concentration of $32 \mathrm{mg} / \mathrm{L}$ was recorded $(t=0)$. Two characteristic peaks of $\mathrm{MB}$ at 664 and $640 \mathrm{~nm}$ were observed using a specific amount of catalyst (about $400 \mathrm{mg} / \mathrm{L}$ ). The catalytic effect was studied by three different experiments, which were carried out as follows.

Initially the dye was subjected to photo irradiation i.e., white light, without catalyst, pure MO and CdS-MO. The color of the MB dye disappeared in all three experiments, whereas in the first study the color of the dye reappeared due to the redox effect of the dye molecule. In the second and third experiments, i.e., in the presence of the catalyst the decolorizations remain the same. The first experiment was carried out in order to check the effectiveness of white light radiation on the decolorization of the dye. The second and third experiments were performed in order to check the adsorption nature of the catalyst. Because the adsorption is an important phenomenon in catalytic studies, more adsorption will lead to better contact with the dye and the catalyst, and which facilitates the electron transfer from the catalyst to the dye, whereby the degradation becomes faster (Ma and Yao 1998). The results show that the adsorption was about $65 \%$ (Fig 5a) and the TOC results confirm that the decolorization is only due to the adsorption. The degradation profile of the $\mathrm{MB}$ dye in the presence of the $\mathrm{CdS}-$ MO catalyst was confirmed by the TOC experiments. The results showed that about $93 \%$ decolorization achieved in the 20th min and the complete decolorization observed at the 75th min. Initially the decolorization was rapid due to the adsorption of dye the molecule on the composite and it was followed by the degradation of the dye molecule.

The degradation profile for the various MB concentrations and the catalyst are shown in Fig. 5b, showing the degradation to be higher at low concentrations of the dye, whereas in high concentration the degradation decreased due to the formation of the dimer dye molecules and also the degraded products occupied the active sites of the composite. The effect of catalyst amount was also tested; the degradation was higher at the higher amount of catalyst, hence the optimum amount of catalyst $400 \mathrm{mg} / \mathrm{L}$ was used for further studies. The contact time between the catalyst and the dye is an important parameter to check the kinetics of degradation (Fig. 5c). The results show that at low catalyst concentration the degradation profile was low. Initially, the decolorization was fast at the low concentration due to the attraction between the dye molecules and the catalyst. This was reduced later, because the absorption of degradation products would occupy the active sites.

The degradation profile was monitored by the TOC experiments. In a typical experiment, even at a lower concentration $(400 \mathrm{mg} / \mathrm{L})$, the compound was completely degraded. The initial concentration of the MB was taken to be $140 \mathrm{mg} / \mathrm{L}$ and the concentration was reduced to 138 and $29 \mathrm{mg} / \mathrm{L}$ respectively at the time of $15 \mathrm{~min}$ after irradiation in visible light with and without catalyst. The irradiation completely degraded the dye in the 75th min. It showed effective decomposition of the dye by the catalyst. The catalyst was recovered and used for further experiments after the first photocatalytic cycle was completed. The guest nano $\mathrm{CdS}$ could quickly transfer the photogenerated electrons through the interlayer into the surfaces of $\mathrm{MO}$ matrix. This is beneficial for retarding the recombination of the photogenerated carriers, and consequently, improving the photochemical activity. The small size of the CdS particles is beneficial for the higher photogenerated voltage generated by the effective electron-hole separation due to the quantum confinement of the nanoparticles. The presence of the higher adsorption nature of the MO facilitates the dye-catalyst interaction, which results in higher degree of degradation. Initially the dye molecule get adsorbed on the catalyst; the catalyst when subjected to photo irradiation will readily transfer the electron from the catalyst to the dye and gets degraded as shown in the reaction (Scheme 2).

The results show that the catalyst efficiency was decreased by about $3 \%$ for MB in the second cycle and 
Fig. 3 a UV-Vis DRS and b Photoluminescence (ext. $390 \mathrm{~nm}$ ) spectrum for CdS-manganese oxide nanocomposite
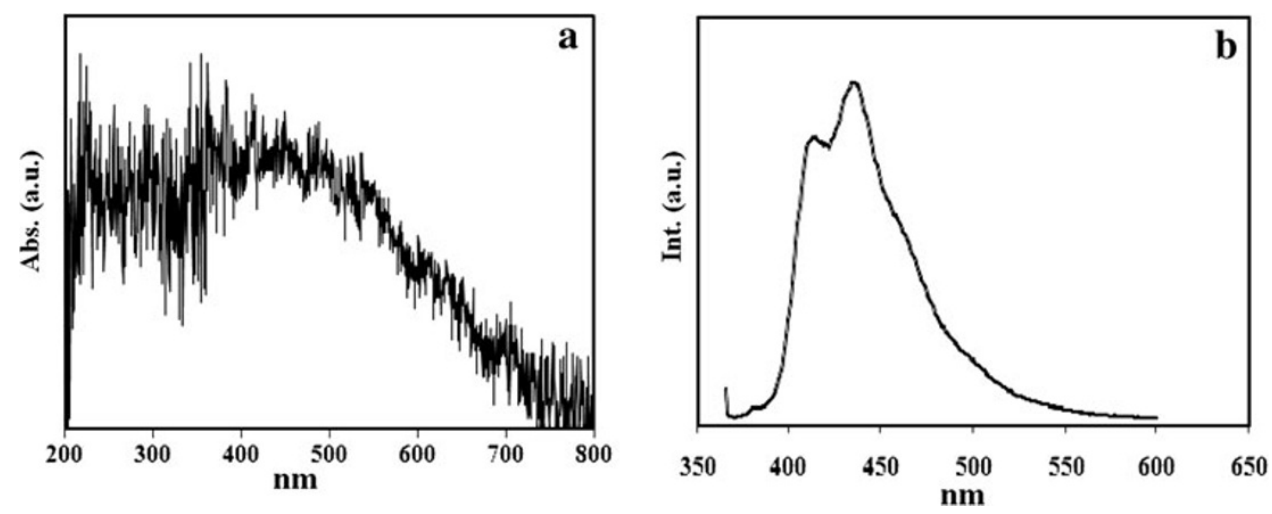

Fig. 4 Transmission electron microscopic images of

a Manganese oxide, b CdS-MO and $\mathbf{c}$ EDX spectrum of CdS-manganese oxide nanocomposite
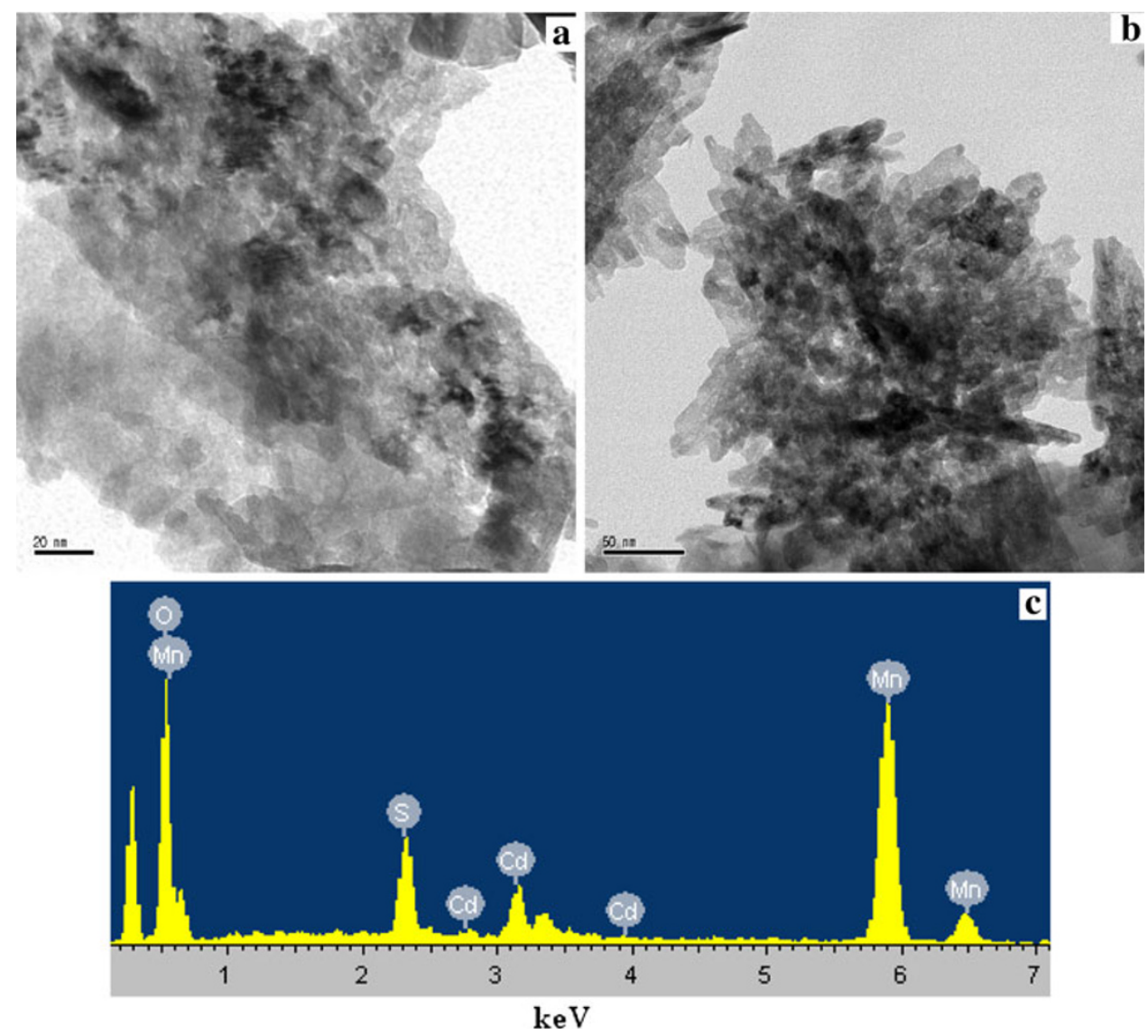

Scheme 2 Reaction mechanism and schematic diagram for the photocatalytic degradation of dye molecules by the MO-CdS nanocomposite
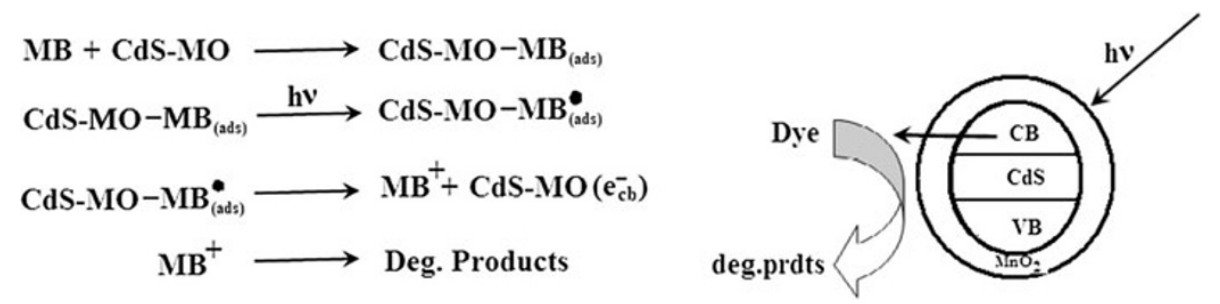

up to the fifth cycle the catalyst showed only $8 \%$ decrease in its efficiency for MB. The catalytic activity was further reduced due to occupied byproducts formed during the degradation of dye molecules. This clearly proves that the catalyst is very efficient and reusable. It is also confirmed by the FTIR analysis. The study on the 
Fig. 5 UV-Vis spectrum of a (a) pure MB dye, adsorption of dye on $(b)$ manganese oxide (d) CdS-MO nanocomposite and photocatalytic degradation of MB dye by $(c)$ manganese oxide $(e) \mathrm{CdS}-\mathrm{MO}$ nanocomposite. b Effect of various concentrations of $\mathrm{MB}$ dye at the CdS-MO nanocomposite $(400 \mathrm{mg} / \mathrm{L})$ and c effect of various amount of CdS-MO nanocomposite catalyst (100, 200, 300 and $400 \mathrm{mg} / \mathrm{L}$ ) for degradation of MB dye under visible light irradiation
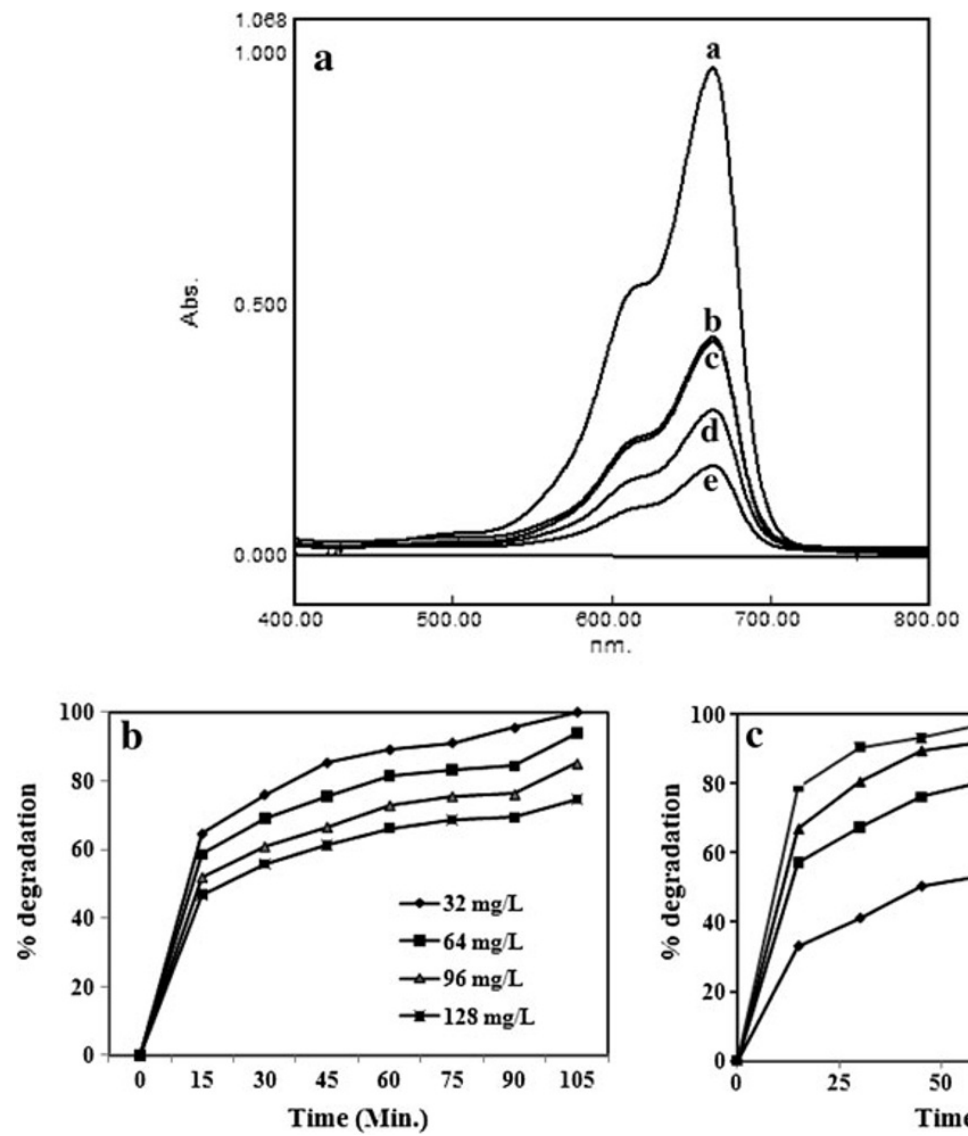

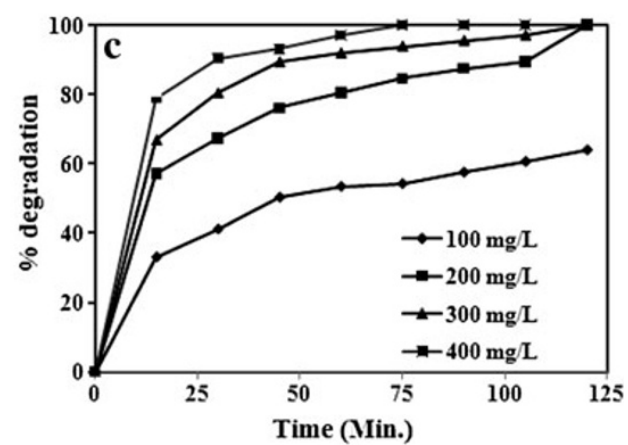

kinetics and mechanistic details of the decolorization and degradation are planned to be carried out in the future.

\section{Conclusion}

The manganese oxide was synthesized by the simple solgel method and $\mathrm{Cd}^{2+}$ was impregnated by the ion exchange and ultrasonic methods, results to the CdS-MO nanocomposite. The sonication of the $\mathrm{Cd}^{2+}-\mathrm{MO}$ resulted in smaller sized nanocomposite and better intercalation of CdS. The resultant nanocomposite shows excellent photocatalytic activity towards the decolorization of the MB dye under visible light. In this nanocomposite MO can act as both solid hosts to produce the CdS and as an electron transfer mediator. The present study reveals that the CdS-MO nanocomposite has great potential for practical photo decolorization and degradation of dyes of industrial effluents.

Acknowledgments The authors thank the management, the principal of Sona College of Technology, Salem and the Vice-Chancellor, Registrar of Karunya University, Coimbatore, and for their kind support and constant encouragement.
Open Access This article is distributed under the terms of the Creative Commons Attribution License which permits any use, distribution and reproduction in any medium, provided the original author(s) and source are credited.

\section{References}

Chen J, Lin JC, Purohit V, Cutlip MB, Suib SL (1997) Photoassisted catalytic oxidation of alcohols and halaogenated hydrocarbons with amorphous manganese oxide. Catal Today 33:205-214

Chen L, Horiuchi T, Mori T (2001) Catalytic reduction of NO over a mechanical mixture of $\mathrm{NiGa}_{2} \mathrm{O}_{4}$ spinel with manganese oxide: influence of catalyst preparation method. Appl Catal A 209:97-105

Ching S, Landrigan JA, Jorgensen ML, Duan N, Suib SL, O'Young CL (1995) Sol-gel synthesis birnessite from $\mathrm{KMnO}_{4}$ and simple sugar. Chem Mater 7:1604-1606

Dameron CT, Reese RN, Mehra RK, Kortan AR, Carroll PJ, Steigerwald ML, Brus LE, Winge DR (1989) Biosynthesis of cadmium sulphide quantum semiconductor crystallites. Nature 338:596-597

Dekany I, Turi L, Kiraly Z (1999) $\mathrm{CdS}, \mathrm{TiO}_{2}$ and $\mathrm{Pd}^{\circ}$ nanoparticles growing in the interlamellar space of montmorillonite in binary liquids. Appl Clay Sci 15:221-239

Feng Q, Kanoh H, Ooi K (1999) Manganese oxide porous crystals. J Mater Chem 9:319-333

Feng Q (2010) Synthesis and applications of manganese oxide nanotubes. In: Kaijma. T (ed) Topic in applied physics. Springer, Berlin, pp 67-76 
Han Z, Zhu H, Bulcock SR, Ringer SP (2005) One step synthesis and structural Features of CdS/Montmorillonite Nanocompoiste. J Phys Chem B 109:2673-2678

Kang L, Zhang M, Liu ZH, Ooi K (2007) IR spectra of manganese oxides with either layered or tunnel structures. Spectrochim Acta A $67: 864-869$

Kannan R, Peera SG, Obadiah A, Vasanthkumar S (2011) $\mathrm{MnO}_{2}$ supported POM-a novel nanocomposite for dye degradation. Dig J Nanomat Biostru 6:829-835

Khaorapaponga N, Ontama A, Youngmea S, Ogawa M (2008) Sold state intercalation and insitu formation of cadminum sulfide in the interlayer space of montmorillonite. J Phys Chem Solid 69:1107-1111

Ma Y, Yao J (1998) Photodegradation of Rhodamine B catalyzed $\mathrm{TiO}_{2}$ thin film. J Photochem Photobiol A Chem 116:167-170

Ma X, Xu F, Chen L, Du Y, Zhang Z (2006) Fabrication of stable $\mathrm{CdS} / \mathrm{CTAB} / \mathrm{Clay}$ with sandwich-like nanostructures. J Nanopart Res 8:661-668

Pal T, Jana NR, Sau TR (1997) Nucleophile induced dissolution if gold. Corros Sci 39:981-986

Ramasubbu A, Vanangamudi A, Muthusubramanian S, Ramachandran MS, Sivasubramanian S (2000) Electrocatalytic studies using silver-clay-a novel material. Electrochem Commun 2:56-64
Sakai N, Ebina Y, Takada K, Sasaki T (2005) Photocurrent generation from semiconductor manganese oxide nanosheets in response to visible light. J Phys Chem B 109:9651-9655

Schuler A, Python M, Olmo MVD, Chambrier ED (2007) Solar Energy. Quantum dot containing nanocomposite thin films for photoluminscent solar concnetrators 81:1159-1165

Segal SR, Suib SL, Foland L (1997) Decomposition of pinacyanol chloride dye using several manganes oxide catalysts. Chem Mater 9:2526-2532

Shangguan W, Yoshida A (2001) Synthesis of photocatalytic properties of CdS-intercalated metal oxides. Solar Energy Mater Solar Cells 69(2):189-194

Shen YF, Zerger RP, DeGuzman RN, Suib SL, McCurdy L, Potter DI, O'Young CL (1993) Manganese oxide octahedral molecular sieves: preparation. Char Appl Sci 260:511-515

Suib SL (2008) Structure, porosity and redox in porous manganese oxide octahedral molecular sieve materials. J Mater Chem 18:1623-1631

Xia GG, Yin YG, Willis WS, Wang JY, Suib SL (1999) Efficient stable catalysis of low temperature carbon monoxide oixdation. J Catal. 185:91-105

Zhang W, Yang Z, Wang X, Zhang Y, Wen X, Yang S (2006) Large scale synthesis of $b-\mathrm{MnO}_{2}$ nanorods and their rapid and efficient catalytic oxidation of methylene blue. Catal Commun 7:408-412 